\title{
Role of nestin expression in angiogenesis and breast cancer progression
}

\author{
ALEKSANDRA NOWAK ${ }^{1}$, JĘDRZEJ GRZEGRZÓŁKA ${ }^{1}$, ALICJA KMIECIK ${ }^{1}$, \\ ALEKSANDRA PIOTROWSKA ${ }^{1}$, RAFAŁ MATKOWSKI ${ }^{2,3}$ and PIOTR DZIĘGIEL ${ }^{1,4}$ \\ ${ }^{1}$ Department of Histology and Embryology, Wroclaw Medical University, 50-368 Wroclaw; ${ }^{2}$ Breast Unit, \\ Department of Surgical Oncology, Lower Silesian Oncology Centre; ${ }^{3}$ Department of Oncology and \\ Surgical Oncology, Wroclaw Medical University, 53-413 Wroclaw; ${ }^{4}$ Department of Physiotherapy, \\ University School of Physical Education, 51-612 Wroclaw, Poland
}

Received August 22, 2017; Accepted November 22, 2017

DOI: $10.3892 /$ ijo.2017.4223

\begin{abstract}
Nestin is an intermediate filament protein and a stem cell marker expressed in several tumours. There is growing evidence of an association between the expression level of nestin and the pathogenesis of triple-negative breast cancer (TNBC). Nestin is also expressed in newly forming tumour vessels and is a valuable marker of ongoing angiogenesis. In this study, we aimed to evaluate the prognostic value of nestin expression in breast tumour cells and to determine whether this expression influences angiogenesis. Immunohistochemical (IHC) analyses were carried out on 124 cases of invasive ductal carcinoma (IDC) of the breast with a panel of murine monoclonal antibodies against nestin, CD31, CD34, SOX-18 and Ki-67. We evaluated nestin expression in tumour and endothelial cells, $\mathrm{Ki}-67$ in tumour cells, and CD31, CD34 and SOX-18 in endothelial cells. Our results demonstrated that nestin expression in tumour cells correlated with the area and number of vessels expressing nestin, CD31, CD34 and SOX-18. We also found a positive correlation between nestin-expressing vessels and SOX-18-expressing vessels. Our results are consistent with those of previous studies, in which nestin expression in endothelial cells was shown to be strongly associated with triple-negative subtype, poorly differentiated G3 tumours, a higher proliferation index and a shorter overall survival. Nestin expression was also examined in human breast cancer cell lines (MCF-7, SK-BR-3, MDA-MB-231 and BO2 cells) representing a different level of tumour aggressiveness and reflecting histological grade. A higher nestin protein level was observed in more aggressive MDA-MB-231 and BO2 cells than in MCF-7 and SK-BR-3 cells.
\end{abstract}

Correspondence to: Miss Aleksandra Nowak, Department of Histology and Embryology, Wroclaw Medical University, Chalubinskiego 6a, 50-368 Wroclaw, Poland

E-mail: alexandra.m.nowak@gmail.com

Key words: nestin, angiogenesis, breast cancer

\section{Introduction}

Breast cancer (BC) is the most common malignancy affecting women worldwide and the leading cause of cancer-related mortality in women. According to GLOBOCAN 2012, 1.7 million women were diagnosed with $\mathrm{BC}$ and 521,000 succumbed to the disease in 2012 (1). Despite well-known mechanisms and pathways contributing to disease progression, $\mathrm{BC}$ remains a clinical challenge. Difficulties in determining an effective treatment regimen arise from the fact that $\mathrm{BC}$ is a heterogeneous disease. Breast tumours exhibit diverse histological patterns and biological features resulting in different clinical behaviours. In 2011, The St. Gallen International Breast Cancer Conference classified BC into four intrinsic subtypes i.e., luminal A, luminal B, human epidermal growth factor receptor 2 (HER2)-positive and triple-negative (TN) (2). The classification was established according to the immunohistochemical (IHC) expression levels of oestrogen receptor (ER) and progesterone receptor (PR), HER2 and Ki-67 antigen. From a clinical perspective, each subtype has different clinical outcomes and different responses to therapeutic options. Triple-negative breast cancer (TNBC) comprises approximately $15 \%$ of all BC cases. The majority of TNBCs fall into the basal-like subtype, which is the most aggressive type of $\mathrm{BC}$ and is characterised by rapid tumour growth and a poor outcome $(3,4)$. The aggressive characteristics of TNBC are presumably associated with an abundance of cancer stem cells (CSCs). However the regulatory mechanisms of this interplay are not yet fully understood (5). Moreover, patients with TNBC cannot benefit from treatment with trastuzumab and anti-oestrogens due to the lack of corresponding receptors. As a result, the identification of novel molecules and treatment targets for TNBC remains a great challenge in modern oncology.

Nestin is an intermediate filament (IF) protein participating in cytoskeletal organisation. It is expressed mostly during embryogenesis in neuroepithelial stem cells (6). However, it is also detected in adults in some types of immature and progenitor cells. Nestin expression has also been observed in progenitor/stem cells isolated from muscles $(7,8)$, teeth (9), the pancreas (10), intestines (11), bone marrow (12), 
hair follicles (13) and other tissues. Nestin expression is rather unique, since it occurs only in very specific cell types and during specific processes, such as development and regeneration $(7,14)$. The expression of nestin is downregulated and replaced by tissue-specific IFs during cell differentiation. Of note, an enhanced nestin expression has been noted in many human neoplasms, such as in central nervous system tumours (15), melanoma (16), breast cancer (17), gastrointestinal stromal tumours (18), prostate cancer (19) and pancreatic cancer (20). In tumours, nestin expression is not limited only to cancer cells. It occurs primarily in newly-formed tumour vessels (21) and cancer stem cells $(22,23)$. In the normal breast, nestin is detected in the basal myoepithelial layer of the ducts and in lobular acinar units (17). Several studies have demonstrated that in $\mathrm{BC}$, nestin expression is almost exclusively limited to a basal-like molecular subtype of TNBCs (17,24-26). In our previous study, we demonstrated that nestin expression in tumour vessels was associated with a more aggressive disease course, a poorer prognosis and the TN phenotype of invasive ductal carcinoma (IDC) (21).

The aim of the present study was to evaluate nestin expression in tumour cells and to determine its prognostic value among patients with $\mathrm{BC}$. We also aimed to determine whether nestin expression in tumour cells may influence the process of angiogenesis. Accordingly, we compared nestin expression in cancer cells to the area and number of vessels expressing vascular antigens i.e., nestin, CD31, CD34 and SOX-18. Finally, we investigated nestin expression in BC cell lines characterised by various degrees of aggressiveness (MCF-7, SK-BR-3, MDA-MB-231 and BO2 cells), which corresponds to different $\mathrm{BC}$ molecular subtypes.

\section{Materials and methods}

Tissue samples and cell lines. The present study was conducted on 124 IDC tissue specimens obtained from patients treated at the Lower Silesian Oncology Centre in Wroclaw, Poland. All patients were treated by mastectomy, quadrantectomy and/or axillary lymph node resection. In total, $11(8.9 \%)$ patients received neoadjuvant chemotherapy and $93(75 \%)$ of patients received adjuvant chemotherapy. A total of $58(46.8 \%)$ patients were treated with radiotherapy. The patients were followed for 64 months (range, 1-80 months). The median follow-up was 80 months. The clinical and pathological data were obtained from the archives of the hospital. Tumour histological type and malignancy grade $(\mathrm{G})$ were determined according to the World Health Organisation (WHO) criteria (27). The patient and tumour characteristics are listed in Table I. The study was approved by the Bioethics Committee of the Wroclaw Medical University and was conducted according to GCP guidelines. Written informed consent was obtained from all participants.

The human BC cell lines, MCF-7, MDA-MB-231 (both from ATCC, Washington, DC, USA), SK-BR-3, (from the Cell Line Collection of the Ludwik Hirszfeld Institute of Immunology and Experimental Therapy of the Polish Academy of Sciences, Wroclaw, Poland) and BO2 (derivative of the MDA-MB-231 cell line isolated from bone metastasis; courtesy of Dr Philippe Clezardin, INSERM U664, Lyon, France), were selected to determine the expression levels of nestin. The BC cell lines were cultured in $\alpha$-MEM supple- mented with $10 \%$ fetal calf serum (FCS; Invitrogen, Carlsbad, CA, USA), 2 mM L-glutamine and $1 \%$ penicillin-streptomycin solution (Gibco, Carlsbad, CA, USA). The normal mammary epithelial cell line, hTERT-HME1 (from ATCC), was cultured in MEGM Bullet kit medium (Lonza, Basel, Switzerland).

$I H C$. The tissue samples were fixed in $4 \%$ buffered formalin, dehydrated and embedded in paraffin. The IHC reactions were examined on the 4- $\mu \mathrm{m}$-thick paraffin sections in Autostainer Link48 (Dako, Glostrup, Denmark). The sections were boiled in EnVision FLEX Target Retrieval Solution ( $\mathrm{pH} \mathrm{9.0,} 97^{\circ} \mathrm{C}$, $20 \mathrm{~min}$ ) using Pre-Treatment Link Platform (both from Dako). To inactivate endogenous peroxidase, the sections were incubated for 5 min with EnVision FLEX PeroxidaseBlocking Reagent (Dako). As primary antibodies, we used a panel of mouse-anti human monoclonal antibodies against the following: nestin (1:100 dilution, OBT1610, Bio-Rad, Hercules, CA, USA), Ki-67 (ready-to-use, IR610, Dako), CD31 (ready-to-use, IR610, Dako), CD34 (ready-to-use, IR632, Dako), SOX-18 (1:25 dilution, sc-166025, Santa Cruz, CA, USA), ER clone 1D5 (ready-to-use, IR654; Dako) and PR clone 636 (ready-to-use, IR068; Dako). The samples were incubated with the primary antibodies for $20 \mathrm{~min}$ at room temperature and then incubated with EnVision FLEX/HRP for $20 \mathrm{~min}$ (Dako). The sections were then incubated for $10 \mathrm{~min}$ with 3,3'-diaminobenzidine (DAB, Dako) as the peroxidase substrate. All slides were counterstained with the EnVision FLEX Hematoxylin (Dako) and closed with coverslips in Dako Mounting Medium (Dako). The expression status of HER2 was determined using the HercepTest and the HER2 FISH pharmDx kit (both from Dako) following the procedure recommended by the manufacturer.

Examination of IHC reactions. The IHC reactions were evaluated using a BX-41 light microscope (Olympus, Tokyo, Japan). The reactions were evaluated simultaneously by two observers in order to achieve a consensus score. Nestin expression in tumour cells was evaluated using the semi-quantitative immunoreactive score (IRS) of Remmele and Stegner (28). The Chalkley count, reflecting an area and number of vessels (29), was assessed on anti-nestin, anti-CD31, anti-CD34 and anti-SOX18-stained slides. Firstly, the slides were briefly examined under low magnification (x100) to identify three areas with the highest vascular density (hot spots). A 25-point Chalkley eyepiece graticule (Pyser Sgi., Edenbridge, UK) was applied to each hot spot at a higher magnification (x200), and oriented to permit the maximum number of points to hit on or within the immunohistochemically stained microvessels (30). The final score for each slide was presented as a mean value from the three hot-spots. The status of ER and PR receptors was scored from 0 to 3 points, depending on the percentage of positive cells ( 0 points, no reaction; 1 point, $1-10 \% ; 2$ points, $11-50 \%$; 3 points, $51-100 \%$ stained cells) (31). HER2 expression was determined using a scale considering the percentage of positive tumour cells and the intensity of the membrane reaction (32). The nuclear expression of Ki-67 antigen was evaluated using a semi-quantitative 5-grade scale as follows: 0 points ( $0 \%$ of cells stained), 1 point (1-10\% of cells stained), 2 points (11-25\% of cells stained), 3 points (26-50\% of cells stained), or 4 points (51-100\% of cells stained). 
Table I. Clinicopathological characteristics of investigated patients with IDC.

\begin{tabular}{|c|c|c|}
\hline Parameters & $\mathrm{n}$ & $\%$ \\
\hline \multicolumn{3}{|l|}{ Age } \\
\hline$\leq 50$ & 36 & 29.0 \\
\hline$>50$ & 88 & 71.0 \\
\hline \multicolumn{3}{|c|}{ Menopausal status } \\
\hline Pre- & 36 & 29.0 \\
\hline Post- & 82 & 66.1 \\
\hline No data & 6 & 4.8 \\
\hline \multicolumn{3}{|c|}{ Tumour size } \\
\hline $\mathrm{T} 1$ & 63 & 50.8 \\
\hline $\mathrm{T} 2$ & 43 & 34.7 \\
\hline $\mathrm{T} 3$ & 11 & 8.9 \\
\hline $\mathrm{T} 4$ & 4 & 3.2 \\
\hline No data & 3 & 2.4 \\
\hline \multicolumn{3}{|c|}{ Lymph nodes } \\
\hline Negative & 62 & 50.0 \\
\hline Positive & 59 & 47.6 \\
\hline No data & 3 & 2.4 \\
\hline \multicolumn{3}{|l|}{ Grade } \\
\hline 1 & 11 & 8.9 \\
\hline 2 & 63 & 50.8 \\
\hline 3 & 50 & 40.3 \\
\hline \multicolumn{3}{|l|}{ pTNM } \\
\hline I + II & 98 & 79.0 \\
\hline III + IV & 23 & 18.5 \\
\hline No data & 3 & 2.4 \\
\hline \multicolumn{3}{|l|}{ ER } \\
\hline Negative & 34 & 27.4 \\
\hline Positive & 90 & 72.6 \\
\hline \multicolumn{3}{|l|}{ PR } \\
\hline Negative & 45 & 36.3 \\
\hline Positive & 79 & 63.7 \\
\hline \multicolumn{3}{|l|}{ HER2 } \\
\hline Negative & 69 & 55.6 \\
\hline Positive & 55 & 44.4 \\
\hline \multicolumn{3}{|l|}{$\mathrm{Ki}-67$} \\
\hline 1 & 56 & 45.16 \\
\hline 2 & 27 & 21.77 \\
\hline 3 & 17 & 13.71 \\
\hline 4 & 18 & 14.52 \\
\hline No data & 6 & 4.84 \\
\hline \multicolumn{3}{|c|}{ Triple-negative } \\
\hline Yes & 19 & 15.3 \\
\hline No & 105 & 84.7 \\
\hline \multicolumn{3}{|c|}{ Overall survival } \\
\hline Deaths & 34 & 27.4 \\
\hline Alive & 88 & 71 \\
\hline No data & 2 & 1.6 \\
\hline
\end{tabular}

IDC, invasive ductal carcinoma; ER, oestrogen receptor; PR, progesterone receptor; HER2, human epidermal growth factor receptor.
Immunocytochemistry (ICC) and immunofluorescence (IF). The investigated tumour cell lines were grown on glass coverslips for $24 \mathrm{~h}$ at $37^{\circ} \mathrm{C}$. The cells were then washed with phosphate-buffered saline (PBS) and then fixed in $4 \%$ paraformaldehyde. After washing, the cells were permeabilised with $0.2 \%$ Triton-X. The ICC reactions in Dako Autostainer Link48 (Dako) according to the procedure described above. The slides were incubated with anti-nestin antibody for $20 \mathrm{~min}$ at room temperature, and then incubated with EnVision FLEX (Dako) to visualize the antigens. For IF reactions, the tumour cell lines were cultured and fixed as stated above. All slides were incubated at $4^{\circ} \mathrm{C}$ overnight with mouse monoclonal antibody against nestin (1:100, OBT1610, Bio-Rad) solved in antibody diluent (Dako). Donkey anti-mouse antibody conjugated with rhodamine $(1: 2,000$, polyclonal; 715-025151 Jackson ImmunoResearch Laboratories, Inc., West Grove, PA, USA) was applied as a secondary antibody. The slides were covered with ProLong ${ }^{\circledR}$ Gold Antifade Mountant mounting medium (Molecular Probes, Eugene, OR, USA) with 4',6-diamidino-2-phenylindole (DAPI) counterstaining. The reactions were viewed using a BX51 fluorescence microscope (Olympus, with DP72 camera and CellF software).

Total RNA isolation and real-time PCR. Total RNA from was isolated from the hTERT-HME1, MCF-7, SK-BR-3, MDA-MB-231 and BO2 cells using the RNeasy Mini kit (Qiagen, Hilden, Germany) according to the manufacturer's instructions. To eliminate genomic DNA, we applied on-column DNase digestion. The quantity and the purity of the RNA were assessed by measuring the absorbance at 260 and 280 nm using a NanoDrop-1000 spectrophotometer (NanoDrop Technologies, Wilmington, DE, USA). First-strand cDNA was synthesised using High-Capacity cDNA Reverse Transcription kits (Applied Biosystems, Foster City, CA, USA). The relative nestin gene (NES) expression level was determined in relation to the expression of the normal mammary epithelial cell line, hTERT-HME1, by quantitative (real-time) PCR with the 7500 Real-Time PCR System and the iTaq Universal Probes Supermix (Bio-Rad), according to the manufacturer's instructions. For the reactions, we applied the following human TaqMan probes: NES Hs04187831_g1 for nestin and ACTB Hs99999903_m1 for $\beta$-actin (both Applied Biosystems). $\beta$-actin was used as a reference gene for determining relative $N E S$ expression in the analysed tumour cell lines. The reactions were carried out in triplicate under the following conditions: initial denaturation at $95^{\circ} \mathrm{C}$ for $10 \mathrm{~min}, 45$ cycles of denaturation at $95^{\circ} \mathrm{C}$ for $15 \mathrm{sec}$, followed by annealing and elongation at $60^{\circ} \mathrm{C}$ for $60 \mathrm{sec}$. The relative mRNA expression level of the NES gene was calculated using the $\Delta \Delta \mathrm{Cq}$ method (33).

Protein extraction and western blot analysis. The cells from the cell culture were trypsinised, washed in PBS and lysed with lysis buffer (50 mM Tris $\mathrm{HCl}, 150 \mathrm{mM} \mathrm{NaCl}, 0.1 \%$ SDS, $1 \%$ Igepal CA-630, 0.5\% sodium deoxycholate) containing $1 \mathrm{X}$ protease inhibitor cocktails (Pierce, Rockford, IL, USA) and $0.5 \mathrm{mM}$ PMSF. Following $20 \mathrm{~min}$ of incubation on ice, the contents were centrifuged at $12,000 \mathrm{xg}$ at $4^{\circ} \mathrm{C}$ for $10 \mathrm{~min}$. The supernatants were collected and whole cell protein concentrations were quantified using the BCA protein assay (Pierce). The protein $(30 \mu \mathrm{g})$ was processed for $6 \%$ SDS-PAGE, transferred 

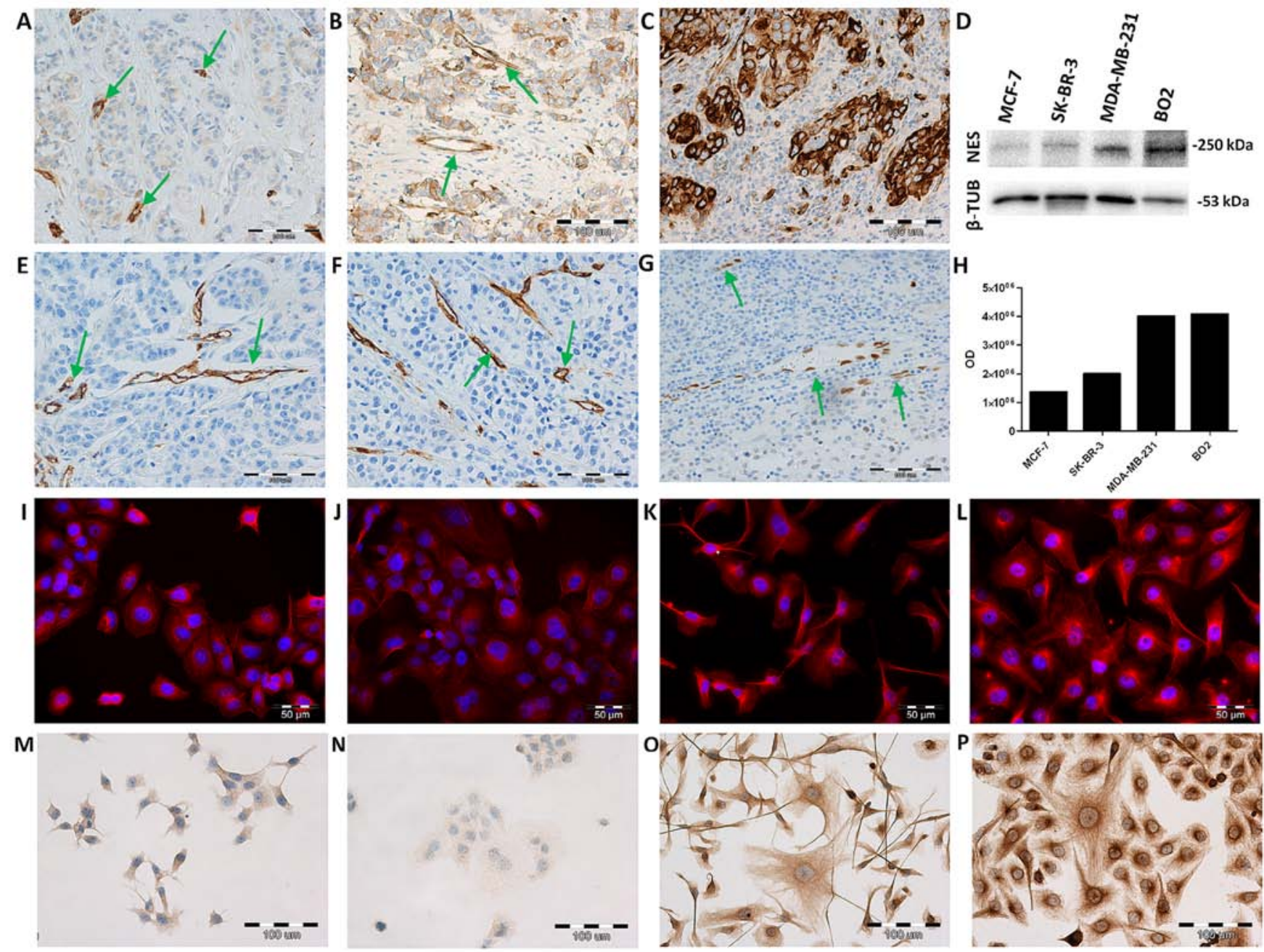

Figure 1. Cytoplasmic expression of nestin in (A) G1, (B) G2 and (C) G3 breast tumour cells and tumour vessels (A-C; green arrows) and in human breast cancer cell lines (E and I) MCF-7, (F and J) SK-BR-3, (G and K) MDA-MB-231 and (H and L) BO2 with the use of (A-C) IHC, (D and H) western blot analysis, (I-L) immunofluorescence and (M-P) immunocytochemistry; cytoplasmic expression of (E) CD31 and (F) CD34 and (G) nuclear expression of SOX-18 in tumour vessels (green arrows). OD, optical density.

onto polyvinylidene fluoride (PVDF) membranes (Immobilon; Millipore, Bedford, MA, USA) and incubated with monoclonal mouse antibody against nestin (1:1,000, OBT1610, Bio-Rad) overnight at $4^{\circ} \mathrm{C}$. The membranes were then incubated with a secondary anti-mouse antibody conjugated with horseradish peroxidase $(1: 3,000$, polyclonal; 715-035-150, Jackson Immunoresearch, Mill Valley, CA, USA) for $1 \mathrm{~h}$ at room temperature, rinsed, and treated with the Immun-Star-HRP Chemiluminescent Kit (Bio-Rad). $\beta$-tubulin, detected with anti- $\beta$-tubulin antibody (rabbit anti-human, 1:1,000, polyclonal; ab6046, Abcam, Cambridge, UK), was used as an internal control to normalize the amounts of nestin at the same membrane after stripping. The protein bands were visualized and quantified with densitometry using Image Lab 3.0 on a Molecular Imager ChemiDoc XRS imaging system (Bio-Rad).

Flow cytometry $(F C)$. For flow cytometric immunophenotyping of intercellular nestin, the cells were fixed and permeabilized with BD Cytofix/Cytoperm ${ }^{\mathrm{TM}}$ (Becton-Dickinson, San Jose, CA, USA) according to the manufacturer's instructions. Subsequently, the cells were stained with mouse monoclonal antibody against human nestin (1:100; OBT1610, Bio-Rad) for $30 \mathrm{~min}$ at room temperature and then labelled with donkey anti-mouse antibody conjugated with fluorescein (1:1,000, polyclonal; 715-096-151 Jackson ImmunoResearch Laboratories). The cells were then analysed by flow cytometry using BD FACSCanto ${ }^{\mathrm{TM}}$ II flow cytometer (Becton-Dickinson) equipped with three lasers: blue $(488 \mathrm{~nm}$, air-cooled, $20 \mathrm{~mW}$ solid state), red (633 nm, $17 \mathrm{~mW} \mathrm{HeNe)} \mathrm{and} \mathrm{violet} \mathrm{(405} \mathrm{nm,}$ $30 \mathrm{~mW}$ solid state). Data were recorded for 20,000 events using BD FACSDiva ${ }^{\mathrm{TM}}$ software (Becton-Dickinson), analysed on the ungated population and presented as histograms using WinMDI2.7 software (Scripps Research Institute, La Jolla, CA, USA).

Statistical analysis. The data were analysed using Prism 5.0 (GraphPad, La Jolla, CA, USA) software. Analysed results are presented as the mean values \pm standard deviation (SD). The associations between the clinicopathological characteristics and the expression of nestin were analysed by the non-parametric Mann-Whitney U test. The differences between nestin expression levels in tumour cells were analysed by one-way analysis of variance with a post hoc Tukey's test. The correlations between the scores of the examined antigens were tested 
A

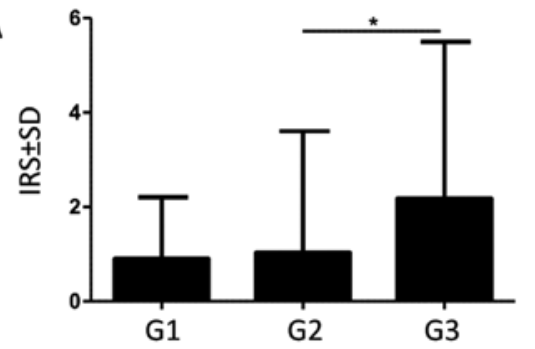

C

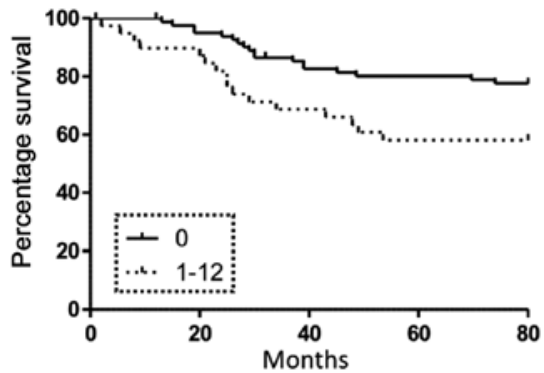

B

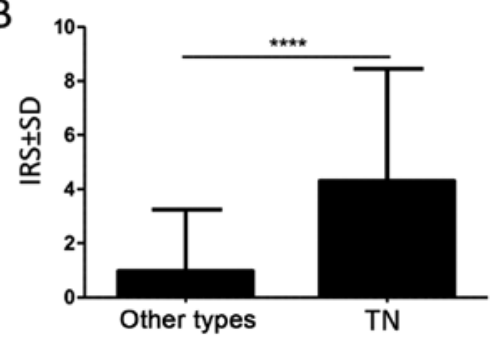

D

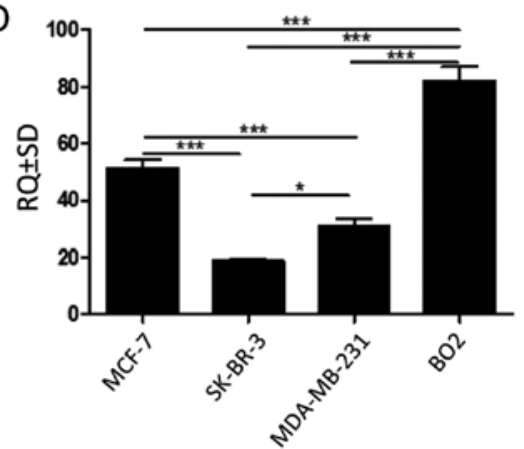

Figure 2. Nestin expression was related to a higher histological grade [(A); $\mathrm{P}=0.024$; Mann-Whitney $\mathrm{U}$ test], the triple-negative (TN) phenotype of breast cancers [(B); $\mathrm{P}<0.0001$; Mann-Whitney $\mathrm{U}$ test] and a shorter overall survival (OS) of patients $[(\mathrm{C}) ; \mathrm{P}=0.02, \mathrm{Mantel-Cox}]$; The IRS $\geq 1$ was used as a cut-off value for nestin expression; mRNA expression of nestin (NES) in human breast cancer cell lines; the highest nestin mRNA expression was observed in metastatic BO2 cells [(D); ${ }^{*} \mathrm{P}<0.05,{ }^{* * *} \mathrm{P}<0.001$; ANOVA, Tukey's post hoc test]. IRS, immunoreactive score; RQ, relative quantity.

using the Spearman rank correlation test. The Kaplan-Meier method and the Mantel-Cox test were used to determine the significance of patient overall survival (OS). In addition, for the analysis of survival, the Cox's univariate and multivariate proportional hazard model was used. Differences were considered statistically significant with a value of $\mathrm{P}<0.05$.

\section{Results}

Immunohistochemical expression of nestin in primary $B C$ tissues. A positive nestin expression was observed in $39(31.5 \%)$ of investigated tumour cases. Nestin expression was observed in the cytoplasm of tumour cells (Fig. 1A-C), tumour vessels (Fig. 1A and B) and in myoepithelial cells of the breast ducts (data not shown). A significantly higher nestin expression in tumour cells was noted in G3 compared to $\mathrm{G} 2$ cases (Fig. 2A; $\mathrm{P}=0.024$; Mann-Whitney $\mathrm{U}$ test). Moreover, our results revealed a significantly higher nestin expression in TNBC (Fig. 2B; P<0.0001; Mann-Whitney $\mathrm{U}$ test). Of note, nestin expression in tumour cells negatively correlated (Spearman rank correlation test) with ER (Fig. 3G; $\mathrm{n}=124, \mathrm{r}=-0.39, \mathrm{P}<0.0001$ ) and PR (Fig. 3H; $\mathrm{n}=124, \mathrm{r}=-0.23$, $\mathrm{P}=0.012$ ), but not with HER2 expression (Fig. 3I; $\mathrm{n}=124$, $\mathrm{r}=-0.11, \mathrm{P}=0.26$ ). A correlation was also noted between nestin expression in tumour cells and $\mathrm{Ki}-67$ expression in the cell nuclei of tumour cells (Fig. $3 F$; $n=112, r=0.25, P=0.0062$; Spearman rank test). Survival data analysis indicated that a postive nestin expression (IRS $\geq 1$ ) in tumour cells was associated with a shorter patient overall survival (Fig. $2 \mathrm{C} ; \mathrm{P}=0.02$; Mantel-Cox test). However, multivariate analysis revealed that nestin was not an independent prognostic factor (Table III). We also found a correlation (Spearman rank correlation test) between nestin expression in tumour cells and the area and number of vessels immunolabelled with antibodies against
CD31 (Fig. 3A; n=105, r=0.24, P=0.01), CD34 (Fig. 3B; n=90, $\mathrm{r}=0.38, \mathrm{P}=0.0002$ ), nestin (Fig. $3 \mathrm{C} ; \mathrm{n}=112, \mathrm{r}=0.19, \mathrm{P}=0.04$ ) and SOX-18 (Fig. 3D; $n=101, r=0.27, P=0.005$ ). A strong correlation was also observed between the area and number of nestin ${ }^{+}$vessels and SOX-18 ${ }^{+}$vessels (Fig. 3E; $\mathrm{n}=101, \mathrm{r}=0.34$, $\mathrm{P}=0.0004$; Spearman rank test).

$m R N A$ nestin level is the highest in the metastatic BO2 cells. The NES mRNA expression level in BC cell lines (MCF-7, SK-BR-3, MDA-MB-231, BO2) was determined by real-time PCR. The relative NES expression was assessed in relation to the expression of the normal mammary epithelial cell line, hTERT-HME1. The highest NES expression was noted in the metastatic $\mathrm{BO} 2$ cell line when compared to the less aggressive MCF-7, SK-BR-3 cells and MDA-MB-231 cells (Fig. 2D; all $\mathrm{P}<0.001$; ANOVA, Tukey's post hoc test). Of note, at the mRNA level, NES expression was higher in the MCF-7 cells than in the more aggressive SK-BR-3 and MDA-MB-231 cells (Fig. 2D; both $\mathrm{P}<0.001$, ANOVA, Tukey's post hoc test).

Nestin protein expression is related to metastatic $M D A-M B-231$ and BO2 cells. The results of ICC and IF reactions revealed the cytoplasmic expression of nestin in all investigated BC cell lines. In both experiments, we observed more intense reactions in metastatic MDA-MB-231 (Fig. 1G and K) and BO2 (Fig. 1H and L) cell lines than in the less aggressive MCF-7 (Fig. 1E and I) and SK-BR-3 cell lines (Fig. 1F and J). The analysis of nestin protein levels by western blot analysis in the $\mathrm{BC}$ cell lines revealed an increased expression in the metastatic MDA-MB-231 and BO2 cells (Fig. 1D). Weaker bands were detected in the MCF-7 and SK-BR-3 cell lines (Fig. 1D). Flow cytometric analysis was performed to determine the expression level of nestin in the investigated BC cell lines. The mean fluorescence intensity (MFI) for nestin was shown as MFI for 

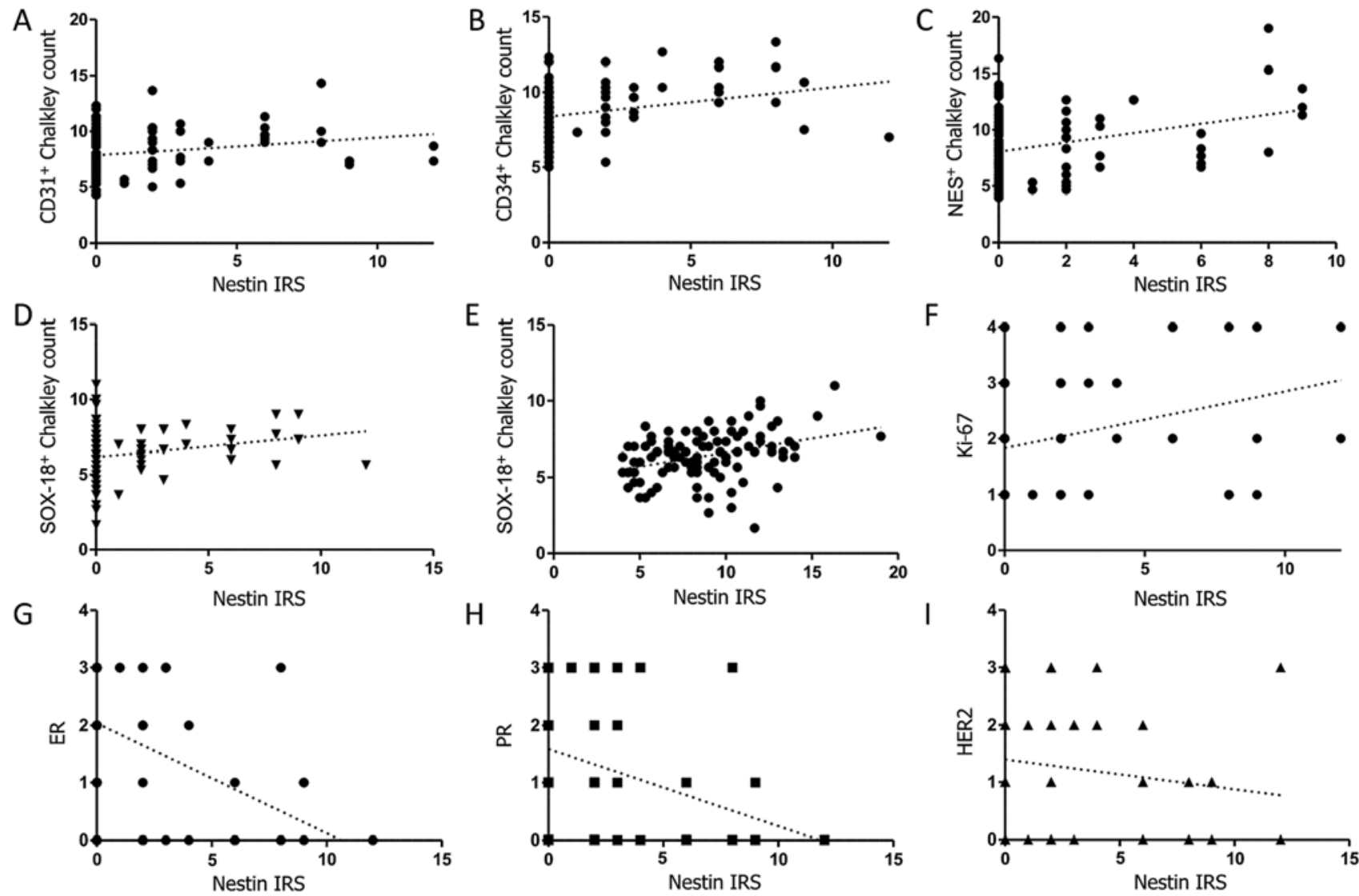

Figure 3. Correlations of nestin expression in tumour cells with the area and number of vessels expressing CD31 [(A); $n-105, r=0.24, P=0.01 ;], C D 34$ [(B); $n=90$, $\mathrm{r}=0.38, \mathrm{P}=0.0002]$, nestin $[(\mathrm{C}) ; \mathrm{n}=112, \mathrm{r}=0.19, \mathrm{P}=0.04]$, SOX-18 [(D); $\mathrm{n}=101, \mathrm{r}=0.27, \mathrm{P}=0.005] ;$ correlation of the area and number of nestin ${ }^{+}$vessels and the area and number of SOX-18+ vessels [(E); $\mathrm{n}=101, \mathrm{r}=0.34, \mathrm{P}=0.0004]$; correlations of nestin expression in tumour cells with the expression of Ki-67 antigen $[(\mathrm{F}) ; \mathrm{n}=112, \mathrm{r}=0.25, \mathrm{P}=0.0062]$ and oestrogen $[(\mathrm{G}) ; \mathrm{n}=124, \mathrm{r}=-0.39, \mathrm{P}<0.0001]$, progesterone $[(\mathrm{H}) ; \mathrm{n}=124, \mathrm{r}=-0.23, \mathrm{P}=0.012]$ and HER2 [(I); $\mathrm{n}=124, \mathrm{r}=-0.11$, $\mathrm{P}=0.26]$ receptors; (all Spearman rank correlation test).

Table II. Mean values of fluorescence for isotype control and nestin in MCF-7, SK-BR-3, MDA-MB-231 and BO2 cell lines.

\begin{tabular}{lccr}
\hline Cell line & Isotype control & I+II antibody & Nestin \\
\hline MCF-7 & 5.88 & 22.48 & 17.2 \\
SK-BR-3 & 8.82 & 18.27 & 9.45 \\
MDA-MB-231 & 8.33 & 28.75 & 20.43 \\
BO2 & 6.61 & 33.09 & 26.48 \\
\hline
\end{tabular}

samples incubated with primary and secondary antibodies minus MFI for the isotype control (Table II). Measurements of the MFI revealed a higher fluorescence intensity in the metastatic MDA-MB-231 and BO2 cells (Table II; MFI=20.43 and MFI=26.48) than in the less aggressive MCF-7 and SK-BR-3 cells (Table II; MFI=17.2 and MFI=9.45).

\section{Discussion}

Accumulating evidence indicates that nestin expression in tumour cells and blood vessels is associated with tumour progression. Nestin expression has been detected in tumour cells of neuroectodermal, epithelial, mesenchymal and germ cell tumours (34). Moreover, in some tumours, nestin expression correlates with the histological grade and is associated with an immature and invasive phenotype of transformed cells (23). The clinical implications of nestin have been well confirmed in $\mathrm{BC}$, where its expression is strongly associated with a poorly differentiated basal-like BC subtype $(17,25,26,35)$, p53 overexpression and a poor prognosis (25). Recently, in a large population-based study, Kruger et al confirmed that nestin expression in tumour cells strongly correlated with the basallike molecular subtype of TNBC, with BRCA1-related BC and with a reduced survival (26).

In this study, we evaluated nestin expression in tumour cells and determined its prognostic value among patients with IDC. Our results were consistent with those of previous studies in which nestin expression in tumour cells was preferentially related to the TN subtype of BC. Moreover, we confirmed that nestin expression negatively correlated with the expression of ER and PR, but not with HER2 expression, as previously described by Gao et al (24). We determined that nestin expression was related to poorly differentiated G3 tumours, a higher proliferation index and a shorter overall survival, which is consistent with the observations by Parry et al (36). In our study, we also aimed to determine whether nestin expression in $\mathrm{BC}$ cells may be associated with the formation of new tumour vessels. Therefore, we compared nestin expression to the area and number of vessels expressing the vascular antigens, nestin, 
Table III. Uni- and multivariate Cox analysis of overall survival.

\begin{tabular}{|c|c|c|c|c|c|c|c|c|}
\hline \multirow[b]{2}{*}{ Parameter } & \multicolumn{4}{|c|}{ Univariate Cox analysis } & \multicolumn{4}{|c|}{ Multivariate Cox analysis } \\
\hline & P-value & HR & HR 95\% lower & HR 95\% upper & P-value & HR & HR 95\% lower & HR 95\% upper \\
\hline Age & 0.16 & 1.98 & 0.77 & 5.1 & & & & \\
\hline Menopausal status & 0.29 & 0.65 & 0.29 & 1.44 & & & & \\
\hline Grade & $<0.005$ & 2.75 & 1.46 & 5.18 & $<0.005$ & 2.69 & 1.37 & 5.26 \\
\hline Stage & $<0.005$ & 7.65 & 3.88 & 15.09 & 0.9 & 0.93 & 0.29 & 2.96 \\
\hline pT & $<0.005$ & 3.96 & 2.62 & 5.98 & $<0.005$ & 3.57 & 2.045 & 6.24 \\
\hline $\mathrm{pN}$ & $<0.005$ & 2.77 & 1.95 & 3.94 & $<0.005$ & 2.95 & 1.64 & 5.3 \\
\hline ER & 0.3 & 1.01 & 0.99 & 1.03 & & & & \\
\hline PR & 0.3 & 1.01 & 0.99 & 1.03 & & & & \\
\hline HER2 & 0.25 & 1.01 & 0.99 & 1.03 & & & & \\
\hline Nestin & 0.67 & 0.98 & 0.91 & 1.06 & & & & \\
\hline
\end{tabular}

Bold font indicates statistical significance. HR, hazard ratio; ER, oestrogen receptor; PR, progesterone receptor; HER2, human epidermal growth factor receptor.

CD31, CD34 and SOX-18. While CD31 and CD34 are common endothelial markers, nestin and SOX-18 are proteins involved in angiogenesis $(21,37-39)$. Our previous study indicated that in BC, nestin is a valuable marker of newly-forming tumour vessels and reflects ongoing angiogenesis (21). In the present study, we demonstrated that nestin expression in tumour cells correlated with the area and number of vessels expressing all investigated antigens i.e., nestin, CD31, CD34 and SOX-18. A positive correlation was noted with vessels expressing the transcription factor, SOX-18, which is an important regulator of vascular development (39). Of note, we also found a positive correlation between the area and number of nestin ${ }^{+}$vessels and SOX-18+ vessels. Ikhapoh et al (40) demonstrated that SOX-18 contributed to the differentiation of mesenchymal stem cells (MSCs) to endothelial cells, whereas nestin is a well-known marker expressed by MSCs (41). An interesting interplay was previously noted between nestin and other transcription factors from the SOX family. In lung adenocarcinoma, SOX-2 promotes NES mRNA transcription (42), while in human melanoma cells SOX-9 and SOX-10 are required for the induction of nestin expression (43). Recently, Feng et al demonstrated that in TNBCs nestin expression was induced by SOX-10, resulting in the regulation of stem-like features of TNBC cells (4).

The association between nestin expression in tumour cells and vascular density has been previously observed in hepatocellular carcinoma (44), ovarian carcinoma (45), glioblastomas (46) and ependymomas (47). To the best of our knowledge, we are the first to demonstrate that nestin expression in BC cells correlates with the area and number of vessels expressing vascular antigens i.e., nestin, CD31, CD34 and SOX-18. Previous studies on hepatocellular carcinoma, ovarian carcinoma and ependymomas have indicated that nestin expression in tumour cells is associated with higher vascular endothelial growth factor (VEGF) levels and a higher CD34 microvessel density $(44,45,47,48)$. He et al (46) demonstrated that in glioblastoma, the population of nestin ${ }^{+}$and $\mathrm{CD} 133^{+}$ cells was concentrated around $\mathrm{CD} 31^{+}$vessels. Moreover, they showed that nestin expression in tumour cells was strongly associated with nestin expression in endothelial cells. Currently nestin is considered a reliable marker of CSCs (23), which are defined as a small subpopulation of undifferentiated cells in tumour tissues that are able to self-renew and to differentiate into various types of tumour cells (23). The interactions between glioblastoma stem-like cells and the vascular niche support the hypothesis that CSCs can transdifferentiate into endothelial cells $(49,50)$. Moreover, CSCs can contribute to tumour angiogenesis by nonendothelial-lining vasculogenic mimicry $(51,52)$. In accordance with these hypotheses, we demonstrated that nestin positivity in tumour cells correlated with the area and number of nestin ${ }^{+}$vessels. However, it still needs to be determined whether a high vascular density may be directly related to nestin expression in tumour cells or whether it is only a hallmark of TNBC $(21,53,54)$. In this study, we also investigated nestin expression in human $\mathrm{BC}$ cell lines (MCF-7, SK-BR-3, MDA-MB-231 and BO2 cells). Depending on the phenotype and aggressiveness, $\mathrm{BC}$ cell lines can be classified into three groups i.e., luminal epithelial (the MCF-7 cells), weakly luminal epithelial-like (the SK-BR-3 cells) and mesenchymal-like (MDA-MB-231 and BO2 cells) (55). MDA-MB-231 and BO2 cells exhibit mesenchymal-like traits and they show no expression of ER, PR and HER2 receptors $(55,56)$. As expected, a considerable increase in nestin protein expression was observed in the highly aggressive MDA-MB-231 and BO2 cells. Less aggressive MCF-7 and SK-BR-3 cell lines with a luminal phenotype expressed nestin protein at lower levels. These results are consistent with the results obtained by IHC where a higher level of nestin expression was related to the TNBC phenotype and high histological grade. Surprisingly, a differential NES gene expression pattern was observed in the MCF-7 and MDA-MB-231 cells. The nestin mRNA level was higher in the less aggressive MCF cells than in the more aggressive SK-BR-3 and MDA-MB-231 cells. However, gene expression is controlled at many different 
stages and in many different ways. The differences between mRNA and protein level might be due to transcriptional and posttranscriptional regulation, protein stability, protein modification and proteolytic cleavage.

In conclusion, in this study, we confirmed that nestin expression in $\mathrm{BC}$ cells is a poor prognostic factor. Based on tissue samples and cell lines we also confirmed that nestin expression was related to the TN phenotype of BC. Moreover, we assume that in $\mathrm{BC}$, nestin expression in tumour cells is associated with enhanced angiogenesis. Although an association has been established, the regulatory mechanisms behind this interplay warrant further clarification.

\section{Acknowledgements}

This study was supported by Wroclaw Medical University Grant Pbmn 192.

\section{References}

1. Torre LA, Bray F, Siegel RL, Ferlay J, Lortet-Tieulent J and Jemal A: Global cancer statistics, 2012. CA Cancer J Clin 65: 87-108, 2015

2. Gnant M, Harbeck N and Thomssen C: St. Gallen 2011: Summary of the Consensus Discussion. Breast Care (Basel): 136-141, 2011

3. Dent R, Trudeau M, Pritchard KI, Hanna WM, Kahn HK, Sawka CA, Lickley LA, Rawlinson E, Sun P and Narod SA Triple-negative breast cancer: Clinical features and patterns of recurrence. Clin Cancer Res 13: 4429-4434, 2007.

4. Feng W, Liu S, Zhu R, Li B, Zhu Z, Yang J and Song C: SOX10 induced Nestin expression regulates cancer stem cell properties of TNBC cells. Biochem Biophys Res Commun 485: 522-528, 2017.

5. Idowu MO, Kmieciak M, Dumur C, Burton RS, Grimes MM, Powers CN and Manjili MH: CD44(+)/CD24(-/low) cancer stem/ progenitor cells are more abundant in triple-negative invasive breast carcinoma phenotype and are associated with poor outcome. Hum Pathol 43: 364-373, 2012.

6. Lendahl U, Zimmerman LB and McKay RD: CNS stem cells express a new class of intermediate filament protein. Cell 60: $585-595,1990$.

7. Sejersen T and Lendahl U: Transient expression of the intermediate filament nestin during skeletal muscle development. J Cell Sci 106: 1291-1300, 1993.

8. Kachinsky AM, Dominov JA and Miller JB: Intermediate filaments in cardiac myogenesis: Nestin in the developing mouse heart. J Histochem Cytochem 43: 843-847, 1995.

9. About I, Laurent-Maquin D, Lendahl U and Mitsiadis TA: Nestin expression in embryonic and adult human teeth under normal and pathological conditions. Am J Pathol 157: 287-295, 2000.

10. Zulewski H, Abraham EJ, Gerlach MJ, Daniel PB, Moritz W, Müller B, Vallejo M, Thomas MK and Habener JF: Multipotential nestin-positive stem cells isolated from adult pancreatic islets differentiate ex vivo into pancreatic endocrine, exocrine, and hepatic phenotypes. Diabetes 50: 521-533, 2001.

11. Vanderwinden JM, Gillard K, De Laet MH, Messam CA and Schiffmann SN: Distribution of the intermediate filament nestin in the muscularis propria of the human gastrointestinal tract. Cell Tissue Res 309: 261-268, 2002.

12. Vogel W, Grünebach F, Messam CA, Kanz L, Brugger W and Bühring HJ: Heterogeneity among human bone marrowderived mesenchymal stem cells and neural progenitor cells. Haematologica 88: 126-133, 2003.

13. Li L, Mignone J, Yang M, Matic M, Penman S, Enikolopov G and Hoffman RM: Nestin expression in hair follicle sheath progenitor cells. Proc Natl Acad Sci USA 100: 9958-9961, 2003.

14. Krum JM and Rosenstein JM: Transient coexpression of nestin, GFAP, and vascular endothelial growth factor in mature reactive astroglia following neural grafting or brain wounds. Exp Neurol 160: 348-360, 1999.

15. Dahlstrand J, Collins VP and Lendahl U: Expression of the class VI intermediate filament nestin in human central nervous system tumors. Cancer Res 52: 5334-5341, 1992.
16. Brychtova S, Fiuraskova M, Hlobilková A, Brychta T and Hirnak J: Nestin expression in cutaneous melanomas and melanocytic nevi. J Cutan Pathol 34: 370-375, 2007.

17. Li H, Cherukuri P, Li N, Cowling V, Spinella M, Cole M, Godwin AK, Wells W and DiRenzo J: Nestin is expressed in the basal/myoepithelial layer of the mammary gland and is a selective marker of basal epithelial breast tumors. Cancer Res 67: 501-510, 2007.

18. Tsujimura T, Makiishi-Shimobayashi C, Lundkvist J, Lendahl U, Nakasho K, Sugihara A, Iwasaki T, Mano M, Yamada N, Yamashita K, et al: Expression of the intermediate filament nestin in gastrointestinal stromal tumors and interstitial cells of Cajal. Am J Pathol 158: 817-823, 2001.

19. Kleeberger W, Bova GS, Nielsen ME, Herawi M, Chuang AY, Epstein JI and Berman DM: Roles for the stem cell associated intermediate filament Nestin in prostate cancer migration and metastasis. Cancer Res 67: 9199-9206, 2007.

20. Matsuda Y, Naito Z, Kawahara K, Nakazawa N, Korc M and Ishiwata $\mathrm{T}$ : Nestin is a novel target for suppressing pancreatic cancer cell migration, invasion and metastasis. Cancer Biol Ther 11: 512-523, 2011.

21. Nowak A, Grzegrzolka J, Paprocka M, Piotrowska A, Rys J, Matkowski R and Dziegiel P: Nestin-positive microvessel density is an independent prognostic factor in breast cancer. Int J Oncol 51: 668-676, 2017.

22. Zhao Z, Lu P, Zhang H, Xu H, Gao N, Li M and Liu C: Nestin positively regulates the $\mathrm{Wnt} / \beta$-catenin pathway and the proliferation, survival and invasiveness of breast cancer stem cells. Breast Cancer Res 16: 408, 2014.

23. Neradil J and Veselska R: Nestin as a marker of cancer stem cells. Cancer Sci 106: 803-811, 2015.

24. Gao N, Xu H, Liu C, Xu H, Chen G, Wang X, Li Y and Wang Y: Nestin: Predicting specific survival factors for breast cancer. Tumour Biol 35: 1751-1755, 2014

25. Liu C, Chen B, Zhu J, Zhang R, Yao F, Jin F, Xu H and Lu P: Clinical implications for nestin protein expression in breast cancer. Cancer Sci 101: 815-819, 2010.

26. Krüger K, Wik E, Knutsvik G, Nalwoga H, Klingen TA, Arnes JB, Chen Y, Mannelqvist M, Dimitrakopoulou K, Stefansson IM, et al: Expression of Nestin associates with BRCA1 mutations, a basal-like phenotype and aggressive breast cancer. Sci Rep 7: 1089, 2017.

27. Lakhani SR, Ellis IO, Schnitt SJ, Tan PH and Vijver MJ (eds.): WHO Classification of Tumours of the Breast. IARC Press, Lyon, 2012.

28. Remmele W and Stegner HE: Recommendation for uniform definition of an immunoreactive score (IRS) for immunohistochemical estrogen receptor detection (ER-ICA) in breast cancer tissue. Pathologe 8: 138-140, 1987 (In German).

29. Offersen BV, Borre M and Overgaard J: Quantification of angiogenesis as a prognostic marker in human carcinomas: A critical evaluation of histopathological methods for estimation of vascular density. Eur J Cancer 39: 881-890, 2003.

30. Fox SB, Leek RD, Smith K, Hollyer J, Greenall M and Harris AL: Tumor angiogenesis in node-negative breast carcinomas--relationship with epidermal growth factor receptor, estrogen receptor, and survival. Breast Cancer Res Treat 29: 109-116, 1994.

31. Goldhirsch A, Ingle JN, Gelber RD, Coates AS, Thürlimann B and Senn HJ; Panel members: Thresholds for therapies: Highlights of the St Gallen International Expert Consensus on the primary therapy of early breast cancer 2009. Ann Oncol 20: 1319-1329, 2009.

32. Mueller-Holzner E, Fink V, Frede $T$ and Marth $C$ : Immunohistochemical determination of HER2 expression in breast cancer from core biopsy specimens: A reliable predictor of HER2 status of the whole tumor. Breast Cancer Res Treat 69: 13-19, 2001.

33. Schmittgen TD and Livak KJ: Analyzing real-time PCR data by the comparative C(T) method. Nat Protoc 3: 1101-1108, 2008

34. Krupkova O Jr, Loja T, Zambo I and Veselska R: Nestin expression in human tumors and tumor cell lines. Neoplasma 57: 291-298, 2010.

35. Piras F, Ionta MT, Lai S, Perra MT, Atzori F, Minerba L, Pusceddu V, Maxia C, Murtas D, Demurtas P, et al: Nestin expression associates with poor prognosis and triple negative phenotype in locally advanced (T4) breast cancer. Eur J Histochem 55: e39, 2011.

36. Parry S, Savage K, Marchiò C and Reis-Filho JS: Nestin is expressed in basal-like and triple negative breast cancers. J Clin Pathol 61: 1045-1050, 2008. 
37. Mokrý J, Cízková D, Filip S, Ehrmann J, Osterreicher J, Kolár Z and English D: Nestin expression by newly formed human blood vessels. Stem Cells Dev 13: 658-664, 2004.

38. Pula B, Olbromski M, Wojnar A, Gomulkiewicz A, Witkiewicz W, Ugorski M, Dziegiel P and Podhorska-Okolow M: Impact of SOX18 expression in cancer cells and vessels on the outcome of invasive ductal breast carcinoma. Cell Oncol (Dordr) 36: 469-483, 2013

39. Downes M and Koopman P: SOX18 and the transcriptional regulation of blood vessel development. Trends Cardiovasc Med 11: 318-324, 2001

40. Ikhapoh IA, Pelham CJ and Agrawal DK: Sry-type HMG box 18 contributes to the differentiation of bone marrow-derived mesenchymal stem cells to endothelial cells. Differentiation 89: 87-96, 2015.

41. Xie L, Zeng X, Hu J and Chen Q: Characterization of nestin, a selective marker for bone marrow derived mesenchymal stem cells. Stem Cells Int 2015: 762098, 2015.

42. Narita K, Matsuda Y, Seike M, Naito Z, Gemma A and Ishiwata T: Nestin regulates proliferation, migration, invasion and stemness of lung adenocarcinoma. Int J Oncol 44: 1118-1130, 2014.

43. Flammiger A, Besch R, Cook AL, Maier T, Sturm RA and Berking C: SOX9 and SOX10 but not BRN2 are required for nestin expression in human melanoma cells. J Invest Dermatol 129: 945-953, 2009

44. Yang XR, Xu Y, Yu B, Zhou J, Qiu SJ, Shi GM, Zhang BH, Wu WZ, Shi YH, Wu B, et al: High expression levels of putative hepatic stem/progenitor cell biomarkers related to tumour angiogenesis and poor prognosis of hepatocellular carcinoma. Gut 59 953-962, 2010.

45. Qin Q, Sun Y, Fei M, Zhang J, Jia Y, Gu M, Xia R, Chen S and Deng A: Expression of putative stem marker nestin and CD133 in advanced serous ovarian cancer. Neoplasma 59: 310-315, 2012.

46. He H, Niu CS and Li MW: Correlation between glioblastoma stem-like cells and tumor vascularization. Oncol Rep 27: 45-50, 2012.

47. Nambirajan A, Sharma MC, Gupta RK, Suri V, Singh M and Sarkar C: Study of stem cell marker nestin and its correlation with vascular endothelial growth factor and microvascular density in ependymomas. Neuropathol Appl Neurobiol 40: 714-725, 2014.
48. Hlobilkova A, Ehrmann J, Knizetova P, Krejci V, Kalita O and Kolar Z: Analysis of VEGF, Flt-1, Flk-1, nestin and MMP-9 in relation to astrocytoma pathogenesis and progression. Neoplasma 56: 284-290, 2009

49. Ricci-Vitiani L, Pallini R, Biffoni M, Todaro M, Invernici G, Cenci T, Maira G, Parati EA, Stassi G, Larocca LM, et al: Tumour vascularization via endothelial differentiation of glioblastoma stem-like cells. Nature 468: 824-828, 2010.

50. Wang R, Chadalavada K, Wilshire J, Kowalik U, Hovinga KE, Geber A, Fligelman B, Leversha M, Brennan C and Tabar V: Glioblastoma stem-like cells give rise to tumour endothelium. Nature 468: 829-833, 2010.

51. Ping YF and Bian XW: Consice review: Contribution of cancer stem cells to neovascularization. Stem Cells 29: 888-894, 2011.

52. Liu TJ, Sun BC, Zhao XL, Zhao XM, Sun T, Gu Q, Yao Z, Dong XY, Zhao N and Liu N: CD133+ cells with cancer stem cell characteristics associates with vasculogenic mimicry in triplenegative breast cancer. Oncogene 32: 544-553, 2013

53. Mohammed RA, Ellis IO, Mahmmod AM, Hawkes EC, Green AR, Rakha EA and Martin SG: Lymphatic and blood vessels in basal and triple-negative breast cancers: Characteristics and prognostic significance. Mod Pathol 24: 774-785, 2011.

54. Krüger K, Stefansson IM, Collett K, Arnes JB, Aas T and Akslen LA: Microvessel proliferation by co-expression of endothelial nestin and $\mathrm{Ki}-67$ is associated with a basal-like phenotype and aggressive features in breast cancer. Breast 22: 282-288, 2013.

55. Lacroix M and Leclercq G: Relevance of breast cancer cell lines as models for breast tumours: An update. Breast Cancer Res Treat 83: 249-289, 2004.

56. DzięgielP,Owczarek T,PlazukE,Gomułkiewicz A, Majchrzak M, Podhorska-Okołów M, Driouch K, Lidereau R and Ugorski M: Ceramide galactosyltransferase (UGT8) is a molecular marker of breast cancer malignancy and lung metastases. Br J Cancer 103: 524-531, 2010. 